\title{
Protocolo de avaliação da probabilidade de uso recreativo de rios e sua aplicação para análise de risco
}

\author{
A protocol for evaluating the probability of the recreational \\ use of rivers and its application in risk analysis
}

Tatiana Figueiredo de Oliveira ${ }^{1}$

Daniel Forsin Buss ${ }^{1}$

${ }^{1}$ Laboratório de Avaliação e Promoção da Saúde Ambiental, Instituto Oswaldo Cruz, Fiocruz. tatibio@ioc.fiocruz.br

\begin{abstract}
Contaminated waters constitute health risks not only due to direct consumption, but also in recreational use. Risk analysis strategies aim to reduce the instances of contaminations and must include the population's perceptions and willingness to assume risks. A rapid and simple method was developed to evaluate the probability of use of recreational waters. Interviews were conducted in municipalities with different ecological conditions, in order to define the factors used by people to decide to use, or otherwise, river waters. After analyzing the results, the "Indice de Probabilidade de Uso Recreativo de Águas (I-PURA)" was elaborated and tested. The index was then employed at 26 river locations representing five of the nine hydrographic regions of Rio de Janeiro state. The frequency of use, water contamination and a Habitat Assessment Visual Index (IAH) was also measured. The I-PURA was correlated with the frequency of use. Furthermore, the I-PURA was not correlated with IAH, showing that user perceptions are different from purely ecological aspects. This tool offers useful information for risk assessment and environmental management. Sites with a high probability of use, or observed use, that are highly contaminated should be prioritized for interventions.
\end{abstract}

Key words Risk analysis, Risk perception, Water quality, Recreational water illnesses, Environmental management
Resumo Águas contaminadas representam um risco à saúde não somente pelo consumo direto, mas também pelo uso recreativo. Estratégias de análise de risco visam à redução dos casos de contaminação e devem incorporar as percepções e aceitação das pessoas em assumir riscos. Um método rápido e simplificado foi desenvolvido para avaliar a probabilidade do uso de águas recreativas. Foram realizadas entrevistas em municípios com condições ecológicas distintas, para elencar fatores que embasam a decisão das pessoas pelo uso dos rios. Em seguida, foi elaborado e realizado pré-teste do Índice de Probabilidade de Uso Recreativo de Águas (I-PURA) que, após ajuste, foi aplicado em 26 balneários de 5 das 9 regiões hidrográficas do estado do Rio de Janeiro. Foram medidas, ainda, a frequência de uso, a contaminação bacteriana da água e um indice de avaliação do habitat (IAH). O I-PURA foi correlacionado à frequência de uso, mas não com o IAH, evidenciando que a percepção dos usuários é diferente de aspectos puramente ecológicos. Este método contribui com a análise de risco e manejo dos recursos hídricos. Locais em que há alta probabilidade de uso, ou uso observado, e alta contaminação são estratégicos para intervenção.

Palavras-chave Análise de risco, Percepção de risco, Qualidade da água, Doenças transmitidas por águas recreativas, Manejo ambiental 


\section{Introdução}

Água, saneamento e higiene estão entre as necessidades humanas mais básicas, e são pré-requisito para a saúde humana e desenvolvimento. Sua má gestão gera fatores de risco, especialmente em ambientes de baixa renda ${ }^{1}$. Águas contaminadas apresentam problema não somente ao consumo direto, mas também por potencialmente contaminar alimentos através de irrigação, além de oferecer riscos à saúde em diversas atividades.

No que diz respeito às águas usadas para recreação, a contaminação pode ocorrer por efluentes domésticos, processos industriais, atividades agrícolas, dejetos de animais domésticos e fauna silvestre ${ }^{2,3}$. Reconhecendo a relevância deste tema, a Organização Mundial de Saúde publicou o documento Guidelines for Safe Recreational Water Environments (em tradução livre, "Diretrizes para a Segurança em ambientes de águas recreativas") com métodos para avaliação dos riscos à saúde pelo uso recreativo de águas e informações para seu monitoramento e gestão. Para águas balneares, a principal preocupação para a saúde pública é a contaminação fecal de origem humana ${ }^{5}$ e de outros animais ${ }^{3}$. Águas contaminadas têm o potencial de transmissão de microorganismos infecciosos pela deglutição, respiração em névoas ou aerossóis, para usuários de piscinas, banheiras de hidromassagem, parques aquáticos, áreas de lazer da água, fontes interativas, lagos, rios ou oceanos ${ }^{2}$. As chamadas RWIs, Recreational Water Illnesses (doenças causadas por águas de recreação) incluem grande variedade de infecções já comprovadamente atribuídas ao contato com águas contaminadas por uso recreativo, como gastroenterites, doenças de pele, ouvido, sistema respiratório, olhos e neurológicas ${ }^{6}$. As RWIs mais comumente relatadas são doenças entéricas, como diarreias, geralmente causadas por microorganismos diversos como Cryptosporidium, Giardia, Salmonella, Shigella, norovirus, rotavirus e Escherichia coli,

Estudos epidemiológicos e relatórios de surtos têm demonstrado a relação entre os efeitos adversos para a saúde e o contato com água recreativa de má qualidade ${ }^{8}$. Nas últimas duas décadas, tem havido um aumento substancial no número de focos de RWI's associados com natação, sobretudo com o aumento dos casos de diarreias ${ }^{9}$. No entanto, é difícil estabelecer a associação direta entre infecção e contato com a água, até porque os registros tendem a não ser completos, pois nem sempre as infecções causam sintomas clínicos². Apesar do aumento no uso de am- bientes de águas doces com finalidade de recreação, há uma carência de estudos e programas de monitoramento para avaliação das condições de balneabilidade no Brasil. O monitoramento deve permitir não apenas o levantamento de informações estratégicas, mas também informações para orientação do público frequentador ${ }^{10,11}$, visando a redução dos riscos e casos de contaminação ${ }^{4}$.

Para a implantação de um sistema de avaliação de risco à saúde por RWIs, deve-se levar em conta informações sobre o potencial de dano estimado através: 1) da identificação dos agentes patogênicos e competência de transmissão; 2) das características do corpo d'água e concentração de patógenos; 3 ) do estado imunológico dos usuários²; além 4) da frequência e forma de uso. Dada a sua natureza distinta, cada um destes fatores é analisado separadamente, mas a avaliação do risco deve considerar as complexas interações entre eles. Dos quatro pontos acima elencados, há diversas pesquisas e atividades dos sistemas de vigilância ambiental e em saúde sobre os dois primeiros itens ${ }^{4}$. Estudos relacionando eventos de contaminação com o estado imunológico dos usuários também são bem conhecidos, sendo crianças, idosos e pessoas com doenças debilitantes as mais suscetíveis². O perfil dos usuários é fundamental, portanto, para o estabelecimento de riscos de contração por RWIs e para traçar as estratégias de comunicação ${ }^{11}$.

Há muitos estudos sobre a percepção e motivações das pessoas em usar praias ${ }^{12-14}$, piscinas ${ }^{15}$ e parques ${ }^{7}$, mas poucos estudos enfocam exclusivamente em balneários de águas doces ${ }^{16-18}$. A percepção das pessoas intermedia a decisão pelo uso ou não das águas, bem como a forma e intensidade e tempo do uso - elementos importantes para a análise de risco, pois dão informações sobre rotas de contaminação e o tempo de contato com os patógenos ${ }^{4,18}$. A condição ambiental pode estimular, ou desestimular, o contato com a água, bem como favorecer seu uso para diferentes fins ${ }^{19}$. O estudo da percepção de risco se baseia na percepção, informação, crença, atitudes, visões, sensações e interpretações da população/grupo populacional/indivíduo sobre um determinado objeto em questão, ao longo se sua trajetória de vida, relacionadas a experiências anteriormente vividas ${ }^{20,21}$. A percepção de riscos à saúde da população é, geralmente, distinta daquela dos especialistas $^{20}$, que enfocam mais na integridade ecológica dos sistemas aquáticos.

Compreender como os usuários percebem a qualidade dos balneários é fundamental para a gestão das bacias hidrográficas, baseada em evi- 
dências. O objetivo deste estudo foi desenvolver um método rápido e simplificado de estimativa da probabilidade de uso de águas de recreação em rios, a partir da percepção da população residente e outros usuários. Baseado no acima exposto, nossas hipóteses são que esta ferramenta forneceria: 1) informações similares às da frequência de uso; 2) informações diferentes de um índice de qualidade ambiental analisando dados puramente ecológicos, pois incorporaria outros elementos de percepção. Esta pesquisa foi submetida e aprovada pelo comitê de ética em pesquisa.

\section{Métodos}

Esta pesquisa foi dividida em três etapas, com o objetivo de representar a probabilidade de uma pessoa decidir por usar ou não áreas balneáveis. Em uma fase exploratória inicial, foi realizado o levantamento de aspectos relevantes da percepção de risco da população usuária ou residente próxima aos trechos de uso recreativo dos rios. Segundo, com estas informações, pré-testes foram elaborados e aplicados e, posteriormente, ajustados para compor o "Índice de Probabilidade de Uso Recreativo de Águas” (I-PURA). A terceira etapa foi o teste do I-PURA em áreas balneáveis (potencialmente ou efetivamente utilizadas para este fim), além de outras áreas notadamente contaminadas, para servirem de controle do modelo.

\section{Levantamento dos critérios adotados para decisão pelo uso de áreas balneáveis}

$\mathrm{Na}$ primeira etapa, foram realizadas entrevistas com perguntas abertas para a população residente e/ou usuários de trechos balneáveis de rios dos municípios de Guapimirim, Sumidouro e Rio de Janeiro, com o objetivo de compreender a percepção sobre os recursos hídricos e os critérios adotados para decidir por sua utilização. Estas áreas foram escolhidas por representarem um gradiente de condições ecológicas. Os 19 entrevistados foram selecionados por serem informantes-chave para este tema, reconhecidos pela equipe da Fiocruz em atividades prévias a este estudo. A equipe da Fiocruz configura-se de biólogos com trabalhos realizados nas áreas da ecologia, parasitologia e saúde coletiva. Em Guapimirim, as regiões escolhidas se localizam no entorno do Parque Nacional da Serra dos Órgãos, nas bacias dos rios Soberbo e Iconha. A área tem bom grau de preservação, mata ciliar, casas com amplos jardins ("sítios") e são utilizadas para visitação, banho e lazer. Os trechos escolhidos para esta etapa se localizam em zonas peri-urbanas. Nestes trechos, os rios possuíam água transparente e fundo de pedras e areia, sem indícios óbvios de esgotos ou outros impactos. No município de Sumidouro, os locais foram escolhidos por representar uma região predominantemente rural com foco na produção de hortaliças e leguminosas. São regiões distantes do centro da cidade, utilizadas para pesca e banho, que possuem fundo de areia, mata ciliar no entorno, facilidade de acesso e profundidade adequada para banho. Por outro lado, observavam-se resíduos sólidos e outros sinais de impactos. A terceira área se localiza na cidade do Rio de Janeiro, no entorno do Parque Nacional da Pedra Branca (Jacarepaguá, atual campus Fiocruz Mata Atlântica). A região sofre grande pressão de urbanização e tem sido modificada. Apesar de próxima a zona urbana com grande ocupação, é bem arborizada e frequentada tanto pela população local, quanto por visitantes para lazer nos fins de semana. Segundo os moradores, apesar de muito utilizados, a qualidade dos rios tem piorado e nota-se resíduos sólidos e pontos de entrada de esgotos.

Foram incluídas no roteiro da entrevista perguntas sobre a frequência e tipo de uso, a percepção sobre a qualidade da água do rio atual e em períodos anteriores e quais os critérios usados para identificar a qualidade do rio. Em uma segunda parte, a entrevista visou identificar se alguns itens específicos, apontados em publicações ${ }^{12,22-24}$ como sendo importantes para pessoas decidirem por utilizar ou não os rios, seriam relevantes àqueles moradores. Foram incluídas perguntas sobre facilidade/dificuldade de acesso, presença de banheiros e comércio, presença e condição da vegetação do entorno, profundidade e substrato do leito do rio, cor da água e indicativos de presença de esgotos e resíduos sólidos. Todas as entrevistas foram realizadas e analisadas pela equipe da Fiocruz.

\section{Elaboração e pré-teste do Índice de Probabilidade de Uso Recreativo de Águas (I-PURA)}

As respostas de cada item das entrevistas foram categorizadas e posteriormente classificadas como "alto", "médio" ou "baixo" desestímulo ao uso, de acordo com a frequência das respostas. Para a elaboração do Índice de Probabilidade de Uso Recreativo de Águas (I-PURA), foi atribuída uma pontuação correspondente a cada categoria/ classificação: muito desestimulante (3), media- 
namente desestimulante (2) e pouco desestimulante (1). As respostas também serviram para a identificação de características estimulantes ao uso e que também receberam pontuações graduadas de acordo com a frequência das respostas (ver Resultados e discussão).

\section{Aplicação e teste do I-PURA em áreas balneáveis do Estado do Rio de Janeiro}

As áreas de uso recreativo das águas incluídas no teste do I-PURA foram identificadas em consultas a sites de turismo (e.g. http://www.turisrio.rj.gov.br/; www.rio.rj.gov.br/riotur; https:// www.tripadvisor.com.br/), de prefeituras, sites com fontes diversas de divulgação de roteiros turísticos (e.g. www.sebrae.com.br/sites/portalsebrae/ufs/rj/institucional/turismo) e consultas diretas nos centros de informações turísticas dos municípios, aos moradores e usuários destas localidades e/ou a pesquisadores familiares com as regiões hidrográficas do RJ. Adicionalmente a estas áreas balneáveis, e para que o índice fosse propriamente testado, foram incluídas seis áreas com alto grau de contaminação e não procuradas para uso recreativo. Assim, o I-PURA foi aplicado em 26 áreas no Estado do Rio de Janeiro.

Em cada trecho foram analisados: 1) as condições de balneabilidade (medida através da análise do número de colônias de E. coli); 2) entrevistas com pelo menos três moradores de cada localidade sobre sua observação da frequência do uso dos rios por ele ou outras pessoas, sendo posteriormente categorizados como baixo (uma ou duas vezes por mês); médio (uma vez por semana) e alto (mais de uma vez por semana); e 3) aplicação de um índice de avaliação do habitat ${ }^{25}$.

A avaliação das condições de balneabilidade de águas doces foi realizada de acordo com as normas estabelecidas pela Resolução CONAMA n ${ }^{\circ} 274 / 2000^{26}$, na qual são categorizadas de acordo com o número de colônias de coliformes termotolerantes e/ou de E. coli. Em cada trecho, foram coletadas duas amostras independentes de $100 \mathrm{~mL}$ de água cada, em recipientes esterilizados, a aproximadamente um metro da margem do rio e abaixo da linha da água. O recipiente foi então vedado, acondicionado em gelo e levado para o laboratório para análise do número de $E$. coli, o que ocorreu a não mais de $6 \mathrm{~h}$ depois da coleta. Para tal, foi utilizado o método enzimático de detecção e enumeração de microrganismos em água (Colilert ${ }^{\circledR}$ IDEXX, Substrato Cromogênico). As amostras independentes serviram para reduzir a chance de obtenção de falsos-negativos e falsos-positivos. Esta metodologia é aprovada pela Agência de Proteção do Meio Ambiente dos Estados Unidos (U.S. Environmental Protection Agency) e está presente no Standard Methods for Examination of Water and Wastewater ${ }^{27}$.

Em cada localidade onde as condições de balneabilidade e as entrevistas de frequência de uso foram realizadas, também foi aplicado um índice de avaliação do habitat (Habitat Assessment Field Data Sheet ${ }^{25}$ ). Através deste método, o investigador avalia visualmente dez parâmetros ambientais (condições para a vida aquática, características do leito, velocidade/regimes de correnteza, deposição de sedimentos, situação do canal de água corrente, alterações no canal, frequências de corredeiras, estabilidade das margens, cobertura vegetal e extensão da mata ciliar) e atribui uma pontuação entre 0 e 20, de acordo com as descrições de cada item. A média dos dez itens estabelece a classe de avaliação do habitat: 0-5 pontos, ruim; 5,1-10 pontos, regular; $10,1-15$ pontos, boa; 15,1-20 pontos, excelente.

\section{Resultados e Discussão}

\section{Levantamento dos critérios adotados para o uso de áreas balneáveis}

$\mathrm{Na}$ primeira etapa, identificamos que apesar de viverem em condições ecológicas distintas, as comunidades apresentavam percepções semelhantes sobre os fatores estimulantes e desestimulantes ao uso dos rios. Os fatores considerados estimulantes para o uso recreativo foram: presença de represas naturais ou artificiais, profundidade suficiente para submergir ao menos parcialmente o corpo, que a água fosse transparente e que o local oferecesse facilidades de acesso e infraestrutura para o lazer e banheiros. Segundo os entrevistados, a coloração da água foi um dos fatores mais desestimulantes ao uso, junto à observação de "lixo", "despachos", "carcaça de animais", "óleo na água”, além da proximidade com fábricas, granjas e chiqueiros (Quadro 1).

\section{Elaboração e pré-teste do Índice de Probabilidade de Uso Recreativo de Águas (I-PURA)}

A percepção de fatores estimulantes ou desestimulantes é determinante para que uma pessoa decida pelo uso ou não do balneário ${ }^{28}$. As respostas aos questionários indicaram que a percepção de alguns fatores desestimulantes não é suficiente 
Quadro 1. Características estimulantes e desestimulantes ao uso (geral) dos rios, e características e situações impeditivas ao lazer, identificados através de questionários com moradores e usuários de áreas balneáveis de rios no estado do Rio de Janeiro.

\begin{tabular}{|c|c|c|c|}
\hline & Estimulante & Desestimulante & Impeditivas ao lazer \\
\hline \multicolumn{4}{|l|}{ Relacionados à quantidade de água } \\
\hline Profundidade & $>50 \mathrm{~cm}$ & $<20 \mathrm{~cm}$ & -- \\
\hline Represa & Presente & -- & -- \\
\hline \multicolumn{4}{|c|}{ Relacionados às características organolépticas da água } \\
\hline Aparência da água & Transparente & $\begin{array}{l}\text { Turva, cinza/ } \\
\text { preta, barrenta, } \\
\text { com óleo }\end{array}$ & $\begin{array}{l}\text { Espuma ou óleo em } \\
\text { abundância }\end{array}$ \\
\hline Odor & -- & Desagradável & Muito desagradável \\
\hline \multicolumn{4}{|l|}{ Relacionados à localidade } \\
\hline Acesso & $\begin{array}{l}\text { Margens } \\
\text { planas e } \\
\text { amplas }\end{array}$ & $\begin{array}{l}\text { Margens } \\
\text { inclinadas }\end{array}$ & Sem acesso \\
\hline Vegetação do entorno & $\begin{array}{l}\text { Presente, mas } \\
\text { não densa }\end{array}$ & $\begin{array}{l}\text { Vegetação muito } \\
\text { densa }\end{array}$ & -- \\
\hline \multicolumn{4}{|l|}{ Relacionados às alterações antrópicas } \\
\hline Construções & $\begin{array}{l}\text { Bar, banheiro, } \\
\text { comércio, } \\
\text { pousada }\end{array}$ & $\begin{array}{l}\text { Fábrica, granja, } \\
\text { chiqueiro (bar } \\
\text { e banheiro } \\
\text { também } \\
\text { apontados como } \\
\text { desestimulantes) }\end{array}$ & $\begin{array}{l}\text { Muitas e/ou grandes } \\
\text { fábricas, matadouros, } \\
\text { curtumes, chiqueiros } \\
\text { e granjas bem ao } \\
\text { lado do rio }\end{array}$ \\
\hline $\begin{array}{l}\text { Resíduos (esgoto, lixo, despacho, óleo, resíduo } \\
\text { hospitalar, carcaça de animais) }\end{array}$ & -- & Presente & Grande quantidade \\
\hline \multicolumn{4}{|l|}{ Relacionados aos aspectos naturais } \\
\hline Leito do rio & Areia, pedra & $\begin{array}{l}\text { Lama, folhas } \\
\text { (pedra também } \\
\text { apontado como } \\
\text { desestimulante) } \\
\end{array}$ & -- \\
\hline Correnteza & -- & -- & Muito forte \\
\hline Fauna aquática & $\begin{array}{l}\text { Peixes, } \\
\text { moluscos }\end{array}$ & -- & -- \\
\hline
\end{tabular}

Elaboração e pré-teste do Índice de Probabilidade de Uso Recreativo de Águas (I-PURA).

para as pessoas deixarem de utilizar a água. Os moradores afirmam usar os rios para lazer e até mesmo para consumo, apesar de identificarem alguns elementos que indicam contaminação. Verificamos pelas respostas que, quando o usuário não é imediatamente repelido ao uso, por alguma(s) característica(s) que identifica, apenas em seguida observa e avalia a presença de fatores estimulantes. A justificativa para o uso de áreas "não-ideais" relacionou-se à falta de outras opções de lazer equivalentes. Estas observações são importantes para auxiliar na construção de um índice que reflita este ponto subjetivo de decisão de não utilizar mais o rio. De acordo com Hunter e Fewtrell ${ }^{29}$ o risco torna-se "aceitável" quando é percebido como menor do que de uma probabi- lidade arbitrariamente definida, menor que um nível já tolerado, ou menor do que uma fração arbitrariamente definida da carga de doenças naquela comunidade; quando o custo de reduzir os riscos excede os economizados ao aceitá-los; quando profissionais de saúde dizem que é aceitável (ou, mais provável, quando omitem dizer que não seria aceitável); ou quando políticos dizem que é aceitável. Em adição a estas, Pendleton et al. ${ }^{14}$ discutem ainda a influência da imprensa na decisão pelo uso.

Seguindo nossas observações e às recomendações da literatura, para o protocolo do I-PURA, primeiro avaliamos as características desestimulantes ao uso. Observações similares foram feitas por alguns autores ${ }^{14,18}$ que demonstram que 
limpeza e cuidados higiênicos são os primeiros itens a serem observados e só depois são observados aspectos naturais e ligados a fatores estimulantes. Em nosso estudo, algumas características e situações foram apontadas como "impeditivas ao uso para lazer" (Quadro 1), ou seja, a condição em que o risco não se torna mais "aceitável". Foram elas: intenso odor desagradável, grande quantidade de espuma, óleo, lixo, esgoto, carcaça de animais ou despachos, presença de muitas e/ou grandes fábricas, matadouros, curtumes, chiqueiros e granjas próximas ao rio, além de quando o rio tem ou está com forte correnteza e quando não há acesso ao rio. Apesar de algumas dimensões de intensidade, como "grande", "muito", "forte" não serem objetivamente mensuráveis - ou, pelo menos, não foi possível defini-los nesta pesquisa - estes itens foram apontados no índice, para capturar esta dimensão subjetiva. $\mathrm{O}$ pré-teste do I-PURA nos trechos balneáveis de rios dos municípios de Guapimirim, Sumidouro e Rio de Janeiro permitiu realizar ajustes na pontuação para registrar o ponto subjetivo de "risco aceitável".

Em resumo, um passo-a-passo da elaboração e aplicação do I-PURA, após o pré-teste é o seguinte:

1. A categorização das respostas das entrevistas indicou onze questões dentre sete categorias gerais de percepção: cor da água, odor, leito do rio, correnteza, presença de resíduos, de construções/uso da terra, e facilidade de acesso. Cada categoria foi então classificada e pontuada de acordo com o nível de desestímulo: "alto" (3 pontos), "médio" ( 2 pontos) ou "baixo" ( 1 ponto) de desestímulo ao uso, de acordo com a frequência das respostas das entrevistas. O I-PURA (Anexo) deve ser aplicado a partir da observação de todas as características locais. Assim, se for observado no trecho que a água é "barrenta", o mesmo é registrado e, segundo o protocolo, esta característica soma 3 pontos de desestímulo ao uso do rio. Se neste trecho hipotético ainda for observado que há lixo/resíduos ( 3 pontos) e que o mesmo se localiza próximo a plantações (1 ponto), o local terá recebido 7 pontos de desestímulo ao uso.

2. Baseado nas respostas dos entrevistados da primeira etapa desta pesquisa foi definido uma pontuação que correspondia ao limite da decisão de não usar o trecho (ver neste item a discussão sobre "risco aceitável"). Baseado nas entrevistas e pré-teste, foi definido que a partir de $>10$ pontos de desestímulo no I-PURA, o trecho deveria ser classificado como tendo "baixa probabilidade de uso para lazer".
3. A presença de um item daqueles categorizados como "inaceitáveis" para uso (intenso odor desagradável, grande quantidade de espuma, óleo, lixo, esgoto, carcaça de animais ou despachos, presença de muitas e/ou grandes fábricas, matadouros, curtumes, chiqueiros e granjas próximas ao rio, além de quando o rio tem ou está com forte correnteza e quando não há acesso ao rio) também determinam a classificação do trecho como "baixa probabilidade de uso para lazer", independente da pontuação.

4. Caso fossem observadas características correspondentes a uma pontuação de $\leq 10$ de desestímulo, sem as características descritas no item 3 acima, procede-se então para uma segunda tabela no I-PURA (Anexo) onde estão listados os fatores que potencialmente estimulam o uso. Durante o pré-teste, observamos que trechos com pontuação $\geq 4$ de estímulo tinham grande uso, ou uso relatado (portanto, "alta probabilidade de usos múltiplos"). Para trechos $<4$ pontos de estímulo são classificados como "média probabilidade de uso".

5. Um aspecto surgido nas entrevistas e que potencialmente restringe o uso específico para lazer é a profundidade do rio. Trechos rasos (i.e. < $50 \mathrm{~cm}$ ) não são atrativos para este fim e isto foi considerado em nossa análise. Desta forma, caso o rio obtenha pontuação $\geq 4$ de estímulo, e for classificado como "raso", o mesmo é classificado como tendo "alta probabilidade de usos múltiplos e média probabilidade de uso para lazer". Se não obtiver classificação de "raso", é classificado como tendo "alta probabilidade de usos múltiplos e alta probabilidade de uso para lazer". Caso o rio obtenha pontuação $<4$, e for classificado como "raso", recebe a classificação "média probabilidade de usos múltiplos e baixa probabilidade de uso para lazer". Se não obtiver classificação de "raso", recebe classificação "média probabilidade de usos múltiplos e média probabilidade de uso para lazer".

\section{Aplicação e teste do I-PURA em áreas balneáveis do Estado do Rio de Janeiro}

Após os ajustes, os 26 rios foram visitados e foi avaliada a probabilidade de uso de águas de recreação (utilizando o I-PURA; Anexo), a frequência do uso, a contaminação da água e aplicado o índice de avaliação do habitat (Quadro 1).

\section{Probabilidade de uso recreativo e frequência de uso observada}

A classificação obtida no I-PURA foi significativamente correlacionada com a frequência 
de uso (Spearman $\mathrm{R}=0,86 ; \mathrm{p}<0.0001)$. Dos 26 trechos analisados neste estudo, em 21 (80\%) o resultado do I-PURA foi equivalente à frequência de uso (Quadro 1). Doze locais apresentaram alta classificação segundo o I-PURA e alta frequência de uso; dois apresentaram média classificação em ambos e sete apresentaram baixa classificação em ambos (Quadro 1). Dos cinco locais que não tiveram a mesma classificação, o valor obtido no I-PURA apontou alta probabilidade de uso, embora tenha sido registrada uma média frequência de uso (Quadro 1). Atribuímos isto à maior distância do rio em relação a estradas e à cidade e, ainda, pelo fato de não serem considerados pontos turísticos por não possuírem atrativos estéticos. Ou seja, estes locais têm alto potencial para uso, e são, de fato, mais frequentados pela população local, conforme indicado nas entrevistas.

Além de entrevistas com usuários, outras alternativas vêm sendo testadas para a estimativa de uso e frequência de áreas balneáveis. Dentre elas, as mais usadas tem sido ferramentas de geoprocessamento para análise de cor e transparência da água, sobretudo em lagos ${ }^{30}$. Considerando os aspectos analisados em nosso estudo, estas ferramentas poderiam ser usadas para estimar o acesso, para medir a proximidade do balneário de indústrias e plantações, e para medir a cobertura vegetal no trecho próximo ao rio. No entanto, como demonstrou nosso estudo, fatores organolépticos (odor da água e visuais como presença de espuma ou óleo no rio, lixo, esgoto carcaça de animal ou despacho), ligados ao banho (pequenas represas e profundidade do rio), ou a presença de amenidades (banheiros, bar) são determinantes para a decisão de uso dos rios (I-PURA). Além disso, não apenas a presença destes fatores foi importante, mas também sua intensidade para determinar se são "impeditivas ao uso para lazer" (p.ex. forte odor desagradável; Quadro 1). A maior parte destas informações só pode ser obtido com a presença do investigador no local. Outros estudos sobre a percepção dos usuários, em diversas partes do mundo, também indicaram que características organolépticas observadas localmente são importantes. Dentre eles, muitos apontam que o odor do rio $^{12,22,24}$, a presença de elementos naturais ${ }^{22}$ ou outros elementos visualmente acessíveis, ligados a indicativos de impacto (e.g. resíduos ${ }^{12,14,28}$ ) influenciam a decisão dos usuários. Moser $^{23}$, em pesquisa com frequentadores de parques na França, registrou os seis critérios que mais influenciavam a decisão de uso pelos usuários: cor e transparência da água, movimento (correnteza), presença de plan- tas (indicador de boa qualidade), detritos flutuantes e odor.

\section{Probabilidade de uso recreativo e índice de avaliação do habitat (IAH)}

Índices ecológicos vêm sendo usados para avaliação ecológica e em planos de gestão de bacias hidrográficas no mundo todo ${ }^{31}$. Em nosso estudo, as classificações obtidas pelo I-PURA não foram correlacionadas às obtidas pelo índice de avaliação do habitat (Tabela 1; Spearman R $=0,35 ; \mathrm{p}=0,08)$. Isto demonstra apenas que a percepção dos usuários, capturada pelo I-PURA, difere da ferramenta de avaliação da condição ecológica (IAH), e não que o IAH não possa ser usado em programas de gestão de bacias. Porém, caso o interesse seja avaliar o risco de exposição, o I-PURA pode representar com mais precisão a chance de uma pessoa utilizar o rio. Este resultado está em acordo com muitos estudos que reportaram que há grande diferença de percepção, dependendo do nível de conhecimento das pessoas $^{32,33}$.

\section{Condição bacteriológica \\ dos balneários analisados}

Das 26 áreas analisadas, 17 são utilizadas como balneários, segundo os moradores. Ainda assim, em todas as áreas visitadas houve relato de utilização do rio para algum fim, mesmo as mais impactadas. Nas áreas usadas como balneário, a situação geral não foi satisfatória usando E. coli como indicador. Segundo a Resolução CONAMA 274/2000 “as águas doces, salobras e salinas destinadas à balneabilidade (recreação de contato primário) terão sua condição avaliada nas categorias própria e imprópria" em função da concentração de coliformes termotolerantes ou E. coli nas águas. As águas consideradas próprias podem ser classificadas como "Excelente", "Muito boa" ou "Satisfatória" (quando em 80\% ou mais de um conjunto de amostras obtidas em cada uma das cinco semanas anteriores, colhidas no mesmo local, houver até 200, 400 ou $800 \mathrm{E}$. coli/100mL, respectivamente). São consideradas "Impróprias" águas onde no trecho avaliado for verificado o não-atendimento aos critérios estabelecidos para as águas próprias (ou seja, acima de 800 E. coli/100mL em $80 \%$ das amostras em cinco semanas), valores acima de 2.000 E. coli/100mL em uma única amostra, ou ainda "se for observada presença de resíduos ou despejos, sólidos ou líquidos, inclusive esgotos sanitários, óleos, graxas e outras substâncias, capazes de oferecer riscos à saúde ou tornar desagradável à re- 
Tabela 1. Localização geográfica do balneário, Índice de Probabilidade de Uso Recreativo de Águas (I-PURA), frequência de uso dos balneários, concentração de Escherichia coli e classificação segundo o Índice de avaliação do habitat (IAH) dos 26 rios analisados. Ver texto para lógica e pontuações.

\begin{tabular}{|c|c|c|c|c|c|}
\hline Localidades (Rio) / Município & $\begin{array}{l}\text { Coordenada } \\
\text { Geográfica }\end{array}$ & I-PURA & $\begin{array}{l}\text { Frequência } \\
\text { de uso }\end{array}$ & E. coli $/ 100 \mathrm{~mL}$ & IAH \\
\hline Rio Sana (Macaé) & $\begin{array}{r}22^{\circ} 22^{\prime} 1.51^{\prime \prime} \mathrm{S} / \\
42^{\circ} 12^{\prime} 18.17^{\prime \prime} \mathrm{O}\end{array}$ & Alta & Alta & 133,4 & Bom \\
\hline Rio Iconha (Guapimirim) & $\begin{array}{r}22^{\circ} 30^{\prime} 47.15^{\prime \prime} \mathrm{S} / \\
42^{\circ} 58^{\prime} 5.66^{\prime \prime} \mathrm{O}\end{array}$ & Alta & Alta & 1986,3 & Regular \\
\hline Rio Lavras (Rio Bonito) & $\begin{array}{r}22^{\circ} 39^{\prime} 51.90^{\prime \prime} \mathrm{S} / \\
42^{\circ} 34^{\prime} 59.4^{\prime \prime} \mathrm{O}\end{array}$ & Alta & Alta & 1769,7 & Regular \\
\hline Rio Bananeiras (Silva Jardim) & $\begin{array}{l}22^{\circ} 28^{\prime} 24.78^{\prime \prime} \mathrm{S} / \\
42^{\circ} 23^{\prime} 49.73^{\prime \prime} \mathrm{O}\end{array}$ & Alta & Alta & 63,2 & Ótimo \\
\hline $\begin{array}{l}\text { Pedra Do Amor (Rio Capivari)/ (Silva } \\
\text { Jardim) }\end{array}$ & $\begin{array}{l}22^{\circ} 38^{\prime} 33.84^{\prime \prime} \mathrm{S} / \\
42^{\circ} 24^{\prime} 48.01^{\prime \prime} \mathrm{O}\end{array}$ & Alta & Alta & 18,5 & Ótimo \\
\hline Cachoeira do Espraiado (Maricá) & $\begin{array}{r}22^{\circ} 51^{\prime} 44.10^{\prime \prime} \mathrm{S} / \\
42^{\circ} 40^{\prime} 38.2^{\prime \prime} \mathrm{O}\end{array}$ & Alta & Alta & 28,9 & Bom \\
\hline Cachoeira da Cascata (Paracambi) & $\begin{array}{l}22^{\circ} 35^{\prime} 43.51^{\prime \prime} \mathrm{S} / \\
43^{\circ} 42^{\prime} 53.34^{\prime \prime} \mathrm{O}\end{array}$ & Alta & Alta & 816,4 & Regular \\
\hline Cachoeira dos Macacos (Rio de Janeiro) & $\begin{array}{l}22^{\circ} 57^{\prime} 46.33^{\prime \prime} \mathrm{S} / \\
43^{\circ} 13^{\prime} 49.99^{\prime \prime} \mathrm{O}\end{array}$ & Alta & Alta & 218,7 & Regular \\
\hline $\begin{array}{l}\text { Córrego Pamparrão (Rio Paquequer)/ } \\
\text { (Sumidouro) }\end{array}$ & $\begin{array}{r}22^{\circ} 02^{\prime} 10.50^{\prime \prime} \mathrm{S} / \\
42^{\circ} 38^{\prime} 34.9^{\prime \prime} \mathrm{O}\end{array}$ & Alta & Alta & 190,4 & Regular \\
\hline $\begin{array}{l}\text { Poço Valério (Rio Macacú)/ (Cachoeiras de } \\
\text { Macacu) }\end{array}$ & $\begin{array}{l}22^{\circ} 26^{\prime} 29.90^{\prime \prime} \mathrm{S} / \\
42^{\circ} 38^{\prime} 11.54^{\prime \prime} \mathrm{O}\end{array}$ & Alta & Alta & 2419,6 & Bom \\
\hline Rio Soberbo (Guapimirim) & $\begin{array}{r}22^{\circ} 30^{\prime} 5.94^{\prime \prime} \mathrm{S} / \\
42^{\circ} 59^{\prime} 51.32^{\prime \prime} \mathrm{O}\end{array}$ & Alta & Alta & 32,3 & Ótimo \\
\hline Rio Inhomirim (Magé) & $\begin{array}{r}22^{\circ} 34^{\prime} 57.06^{\prime \prime} \mathrm{S} / \\
43^{\circ} 11^{\prime} 4.14^{\prime \prime} \mathrm{O}\end{array}$ & Alta & Alta & 2419,6 & Regular \\
\hline $\begin{array}{l}\text { Taquara (Cachoeira das Dores)/ (Duque de } \\
\text { Caxias) }\end{array}$ & $\begin{array}{l}22^{\circ} 35^{\prime} 55.00^{\prime \prime} \mathrm{S} / \\
43^{\circ} 14^{\prime} 17.76^{\prime \prime} \mathrm{O}\end{array}$ & Alta & Média & 98,8 & Regular \\
\hline $\begin{array}{l}\text { Xerém (Cachoeira de Xerém)/ (Duque de } \\
\text { Caxias) }\end{array}$ & $\begin{array}{r}22^{\circ} 33^{\prime} 38.76^{\prime \prime} \mathrm{S} / \\
43^{\circ} 19^{\prime} 9.04^{\prime \prime} \mathrm{O}\end{array}$ & Alta & Média & 133,6 & Bom \\
\hline $\begin{array}{l}\text { Boca Do Mato (Rio Macacú)/ (Cachoeiras } \\
\text { de Macacu) }\end{array}$ & $\begin{array}{r}22^{\circ} 25^{\prime} 7.54^{\prime \prime} \mathrm{S} / \\
42^{\circ} 37^{\prime} 17.03^{\prime \prime} \mathrm{O}\end{array}$ & Alta & Média & 209,8 & Bom \\
\hline Represa (Jacarepaguá)/ Rio de Janeiro & $\begin{array}{r}22^{\circ} 56^{\prime} 5.16^{\prime \prime} \mathrm{S} / \\
43^{\circ} 23^{\prime} 58.72^{\prime \prime} \mathrm{O}\end{array}$ & Alta & Média & 88,6 & Ótimo \\
\hline Rio Imbaú (Silva Jardim) & $\begin{array}{r}22^{\circ} 37^{\prime} 4.76^{\prime \prime} \mathrm{S} / \\
42^{\circ} 28^{\prime} 29.06^{\prime \prime} \mathrm{O}\end{array}$ & Alta & Média & 2419,6 & Regular \\
\hline $\begin{array}{l}\text { Reflorestamento (Rio Capivari)/ (Silva } \\
\text { Jardim) }\end{array}$ & $\begin{array}{r}22^{\circ} 38^{\prime} 30.40^{\prime \prime} \mathrm{S} / \\
42^{\circ} 24^{\prime} 00.0^{\prime \prime} \mathrm{O}\end{array}$ & Média & Média & 686,7 & Regular \\
\hline Rio Encanto (Sumidouro) & $\begin{array}{r}22^{\circ} 02^{\prime} 51.00^{\prime \prime} \mathrm{S} / \\
42^{\circ} 37^{\prime} 02.9 ” \mathrm{O}\end{array}$ & Média & Média & 613,1 & Regular \\
\hline Rio Cambucaes (Silva Jardim) & $\begin{array}{l}22^{\circ} 36^{\prime} 34.62^{\prime \prime} \mathrm{S} / \\
42^{\circ} 23^{\prime} 33.79^{\prime \prime} \mathrm{O}\end{array}$ & Baixa & Baixa & 254,2 & Regular \\
\hline $\begin{array}{l}\text { FIOCRUZ Mata Atlântica (Jacarepaguá)/ } \\
\text { Rio de Janeiro }\end{array}$ & $\begin{array}{r}22^{\circ} 56^{\prime} 9.53^{\prime \prime} \mathrm{S} / \\
43^{\circ} 23^{\prime} 59.52^{\prime \prime} \mathrm{O}\end{array}$ & Baixa & Baixa & 2419,6 & Regular \\
\hline Rio Caceribú (Itaboraí) & $\begin{array}{l}22^{\circ} 42^{\prime} 43.79^{\prime \prime} \mathrm{S} / \\
42^{\circ} 48^{\prime} 31.28^{\prime \prime} \mathrm{O}\end{array}$ & Baixa & Baixa & 48,7 & Bom \\
\hline Rio Cabuçú (Itaboraí) & $\begin{array}{l}22^{\circ} 48^{\prime} 57.47^{\prime \prime} \mathrm{S} / \\
42^{\circ} 53^{\prime} 19.34^{\prime \prime} \mathrm{O}\end{array}$ & Baixa & Baixa & 2419,6 & Regular \\
\hline Rio Alcântara (São Gonçalo) & $\begin{array}{r}22^{\circ} 50^{\prime} 23.35^{\prime \prime} \mathrm{S} / \\
43^{\circ} 0^{\prime} 37.31^{\prime \prime} \mathrm{O}\end{array}$ & Baixa & Baixa & 2419,6 & Ruim \\
\hline Rio Imboaçú (São Gonçalo) & $\begin{array}{r}22^{\circ} 50^{\prime} 47.91^{\prime \prime} \mathrm{S} / \\
43^{\circ} 2^{\prime} 55.07^{\prime \prime} \mathrm{O}\end{array}$ & Baixa & Baixa & 2419,6 & Ruim \\
\hline Rio Brandoa (São Gonçalo) & $\begin{array}{r}22^{\circ} 50^{\prime} 32.24^{\prime \prime} \mathrm{S} / \\
43^{\circ} 4^{\prime} 59.53^{\prime \prime} \mathrm{O}\end{array}$ & Baixa & Baixa & 2419,6 & Ruim \\
\hline
\end{tabular}


creação ou outros fatores que contra-indiquem, temporária ou permanentemente, o exercício da recreação de contato primário”. A lógica deste sistema de avaliação se apoia em estudos que apontam uma relação significativa entre o número de colônias de E. coli e a incidência de doenças pelo uso recreativo das águas ${ }^{2,4,8,18,34}$, ainda que alguns autores discutam que outros indicadores são mais adequados do que o uso exclusivo de coliformes para este fim ${ }^{9}$.

Oito balneários analisados foram considerados impróprios (> 2.000 E. coli/100mL; Tabela 1) e em 14 localidades identificamos lixo, carcaça ou despacho, fatores desestimulantes ao uso do rio e que podem causar contaminação. A presença de fábrica, indústria, matadouro, curtume ou granja foi identificada em 9 localidades.

A técnica utilizada nesse trabalho para identificação de E. coli foi o método Colilert ${ }^{\circledR}$ IDEXX de Substrato Cromogênico. Alguns pesquisadores verificaram que este método apresentou sensibilidade similar às técnicas convencionais (fermentação em tubos múltiplos ou por membrana filtrante), com menor tempo e custo de processamento $^{35}$. Por outro lado, alguns estudos indicaram que o Colilert ${ }^{\circledR}$ produziu uma porcentagem considerável de falsos-positivos ${ }^{36,37}$. No presente estudo, foi realizada uma coleta por local com amostras em duplicata, e os resultados foram consistentes: não foram observados casos de presença de E. coli em uma das réplicas e ausência na outra. Além disso, os valores obtidos pelo método Colilert ${ }^{\circledR}$ em uma das amostras foi sempre similar ao da segunda amostra independente (variação máxima de 12,7\% em um rio, Iconha, $1.986,3$ e $1.732,9$ E. coli/100mL em cada amostra; em todas as demais a variação foi menor do que $4 \%$ ).

\section{Contribuições desta abordagem para análise de risco}

A análise combinada dos dados bacteriológicos e da probabilidade de uso auxilia na identificação de locais prioritários e dão indicativos da ação necessária. Por exemplo, naqueles em que há alta/média probabilidade de uso e alta concentração bacteriana (Figura la e b) são potencialmente locais com maior probabilidade de contaminação dos usuários por RWIs e devem ser alvos prioritários de intervenção. As áreas que possuem baixa contaminação e que apresentam alta probabilidade de uso devem ser constantemente monitoradas e ações para a manutenção do status atual devem ser postas em prática. Onde há baixa probabilidade de uso (por conta da percepção de ambientes inadequados para contato), são necessárias ações de recuperação ambiental e tratamento das fontes contaminantes e naquelas em que há baixa contaminação, com investimentos moderados e criação de atrativos, pode ser possível transformá-las em áreas adequadas para o uso recreativo (Figura la e b).

Nossos resultados mostraram que as pessoas tendem a "aceitar riscos percebidos", porém que há um ponto - que buscamos capturar com a ferramenta - em que o uso é evitado. Para a gestão de bacias, estas informações são importantes, sobretudo porque alguns estudos nesta área mostraram relação entre uso da água e RWIs: Azevedo $^{38}$, na região da Baía de Sepetiba-RJ, e França et al., 2014 ${ }^{39}$, sobre a multirresistência a antibióticos de bactérias heterotróficas (Salmonella sp., Shigella sp., Legionella sp.). Além disto, o fator subjetivo da percepção das pessoas afeta não apenas a decisão de uso ou não de balneários, mas também na valoração monetária de propriedades ${ }^{40}$, outro aspecto importante para a gestão de bacias hidrográficas.

\section{Conclusões}

O fato do balneário apresentar impacto ou apenas apresentar fatores desestimulantes não caracteriza um impeditivo ao contato do banhista para uso, o que pode estar relacionado à falta de opções melhores para lazer, levando o morador ainda assim a utilizar o rio. Além disso, o índice I-PURA apresentou similaridade em comparação à frequência do uso (em mais de $80 \%$ dos balneários) demonstrando que o mesmo reproduz a realidade observada na prática diária do morador, quando utiliza como variáveis parâmetros perceptivos dos indivíduos.

A identificação de índice I-PURA alto ou médio fixados pela percepção dos usuários juntamente com níveis de E. coli alto, definem os balneários como áreas com potencial risco de contaminação dos banhistas de se infectarem com doenças de veiculação hídrica mais graves, tais como disenteria, cólera, hepatite A e febre tifoide.

A uniformização das informações obtidas nas análises de percepção dos usuários dos balneários em um índice único é uma tarefa difícil. No entanto, ainda que a percepção dependa de fatores como idade, sexo, experiência, dentre outros elementos culturais ${ }^{20}$, muitos estudos demonstraram que a variabilidade de percepção de pessoa a pessoa é geralmente menor do que a 


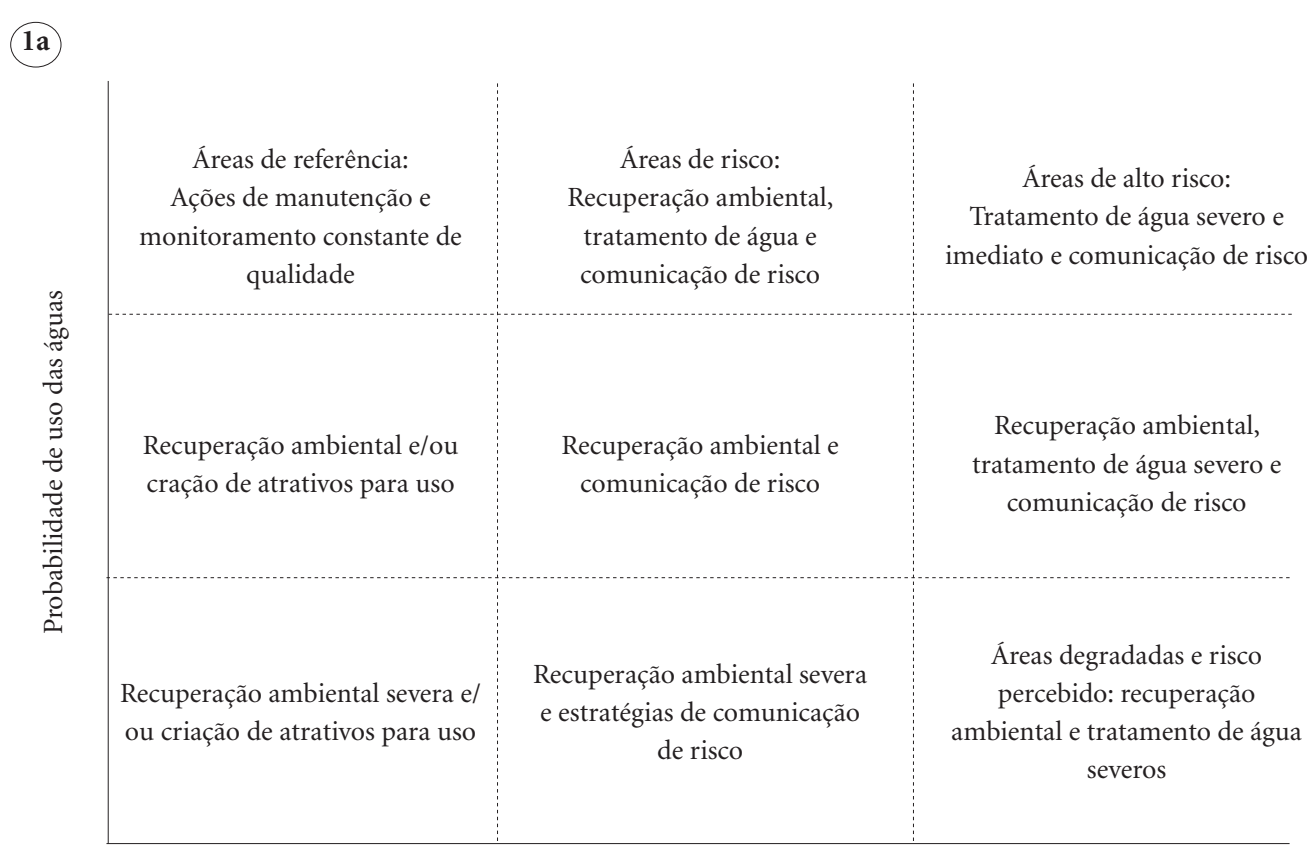

Contaminação das águas

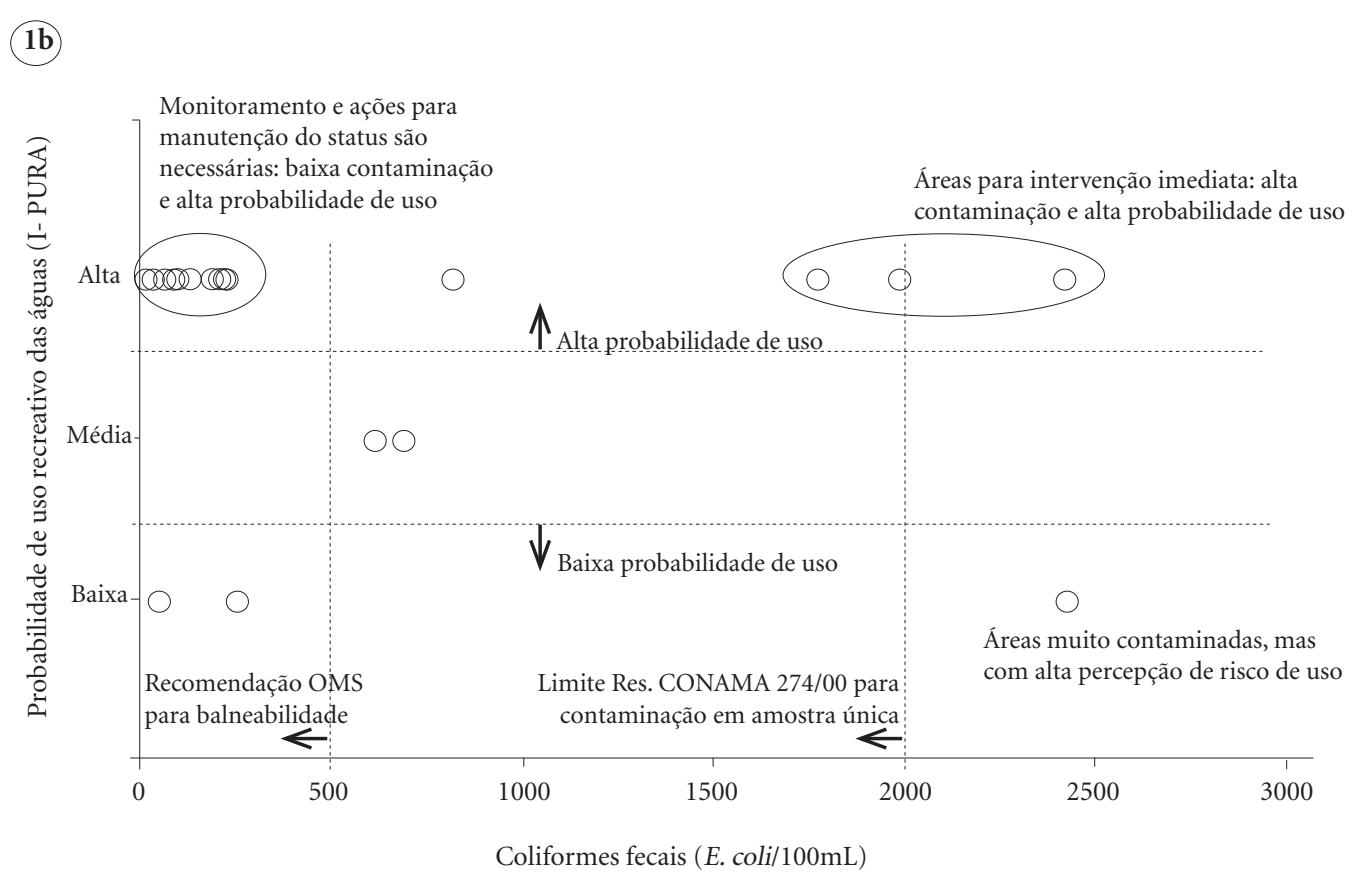

Figura 1a e 1b. Análise combinada dos dados bacteriológicos e da probabilidade de uso auxilia na identificação de locais prioritários e respectiva a ação necessária.

diferença de percepção entre dois ambientes distintos ${ }^{41,42}$. Algumas informações que podem ser obtidas por técnicas de geoprocessamento podem ser testadas como proxy do uso e frequência, mas em geral, em nosso estudo, fatores organolépticos foram aspectos importantes da tomada de decisão pelo uso do rio. Além disso, o I-PURA diferiu do IAH que avalia aspectos ecológicos 
dos rios. As vantagens do I-PURA para uso na análise de risco é que ele reflete a percepção dos usuários, servindo de estimativa de uso, podendo ser aplicado mesmo na ausência de usuários no momento da visita.

Uma das vantagens do uso do questionário do I-PURA, é que ele permite a aplicação sem a presença de moradores ou outros informantes na região, simplesmente pela observação direta do pesquisador, o que acelera, facilita e torna possível o processo de avaliação do balneário mesmo na ausência de usuários no momento da visita. Índices de qualidade da água são destinados a fornecer uma ferramenta simples e compreensível para os gestores e os tomadores de decisão sobre a qualidade e os possíveis usos do corpo hídrico.

$\mathrm{O}$ índice proposto possibilita integrar as variáveis que mais podem contribuir para uma avaliação integrada de condições de balneabilidade, além de identificarem aspectos estéticos das águas dos balneários, proporcionando assim uma ferramenta importante para fins de gestão, pela fácil interpretação do índice. As avaliações dos balneários poderiam contribuir para a elaboração de planos de ação por parte dos órgãos ambientais, a partir da possibilidade de identificação das reais condições de balneabilidade e de suas principais fontes de pressão, haja vista a possibilidade de interferência de fatores ambientais.

Todavia, as avaliações visam subsidiar o processo de gestão do uso recreacional das águas, sendo necessário que o monitoramento de condições de balneabilidade também atenda a demanda por informações sobre o diagnóstico de balneários, de forma a orientar o público frequentador.

A metodologia de avaliação de condições de balneabilidade aqui proposta, apresenta avanços importantes em relação aos procedimentos estabelecidos pela Resolução CONAMA 274/2000, pois incorpora novos fatores/variáveis de risco aos usuários, bem como pelo sistema de classificação dos balneários através de monitoramento. Deste modo, permite-se um diagnóstico mais eficaz das condições de balneabilidade oferecendo maior segurança ao público frequentador. Assim, esta proposta metodológica consiste em um importante instrumento para o aprimoramento e atualização da resolução vigente no país.

Faz-se necessária a realização de novas pesquisas, bem como o desenvolvimento de novos trabalhos epidemiológicos, utilizando dados referentes aos balneários brasileiros, que certamente contribuirão para o aperfeiçoamento da metodologia proposta.

Deste modo, o estabelecimento de novos critérios para o uso recreacional de contato primário em águas doces no Brasil, carece de uma profunda reflexão, com a participação dos cientistas atuantes em órgãos de monitoramento e gerenciamento ambiental, além de outros atores envolvidos na gestão das águas no país, e ainda da comunidade científica atuante nas áreas correlatas.

\section{Colaboradores}

TF Oliveira, trabalhou na execução do trabalho de campo, definição de metodologia, análise dos resultados, discussão e redação final. DF Buss, trabalhou na definição de metodologia, análise dos resultados, discussão e redação final.

\section{Agradecimentos}

À CAPES, pela concessão de bolsa para a primeira autora, e ao $\mathrm{CNPq}$ pelo financiamento. Agradecemos a R.A. Cunha pelo material ilustrativo que faz parte do protocolo I-PURA. 


\section{Referências}

1. World Health Organization (WHO), United Nations Children's Fund (UNICEF). WHO/UNICEF. Joint Monitoring Programme (JMP) for water supply and sanitation. 2013. [acessado 2015 Mar 5]. Disponível em: http://www.wssinfo.org/data-estimates/introduction/.

2. Pond K. Hazard Identification and Factors Related to Infection and Disease. In: Pond K. Water and disease: plausibility of associated infections: acute effects, sequela and mortality. Geneva: World Health Organization; 2005. p. 25-26.

3. Soller JA, Schoen ME, Bartrand T, Ravenscroft JE, Ashbolt NJ. Estimated human health risks from exposure to recreational waters impacted by human and nonhuman sources of faecal contamination. Water Research 2010; 44(16):4674-4691.

4. World Health Organization (WHO). Faecal pollution and water quality. In: Guidelines for safe recreational water environments - coastal and fresh waters. Geneva: WHO; 2003. v. 1, p.51-96.

5. Colford Junior JM, Wade TJ, Schiff KC, Wright CC, Griffith JF, Sandhu SK. Water quality indicators and the risk of illness at beaches with non-point sources of fecal contamination. Epidemiology 2007; 18(1):27-35.

6. Center for Disease Control and Prevention (CDC). Surveillance for Waterborne Disease Outbreaks and Other Health Events Associated with Recreational Water - United States, 2007-2008. In: Surveillance for Waterborne Disease and Outbreaks Associated with Recreational Water Use and Other Aquatic Facility-Associated Health Events - United States, 2005-2006 and Surveillance for Waterborne Disease and Outbreaks Associated with Drinking Water and Water not Intended for Drinking - United States, 2007-2008. Washington: CDC; 2008. p. 2-36.

7. McClain J, Bernhardt JM, Beach MJ. Assessing Parents' Perception of Children's Risk for Recreational Water Illnesses. Emerg Infect Dis 2005; 11(5):670-676.

8. Wade TJ, Sams EA, Beach MJ, Collier SA, Dufour AP. The incidence and health burden of earaches attributable to recreational swimming in natural waters: a prospective cohort study. Environmental Health 2013; 12:67.

9. CDC. [Healthy Swimming] 2016. [acessado $2015 \mathrm{Mar}$ 5]. Disponível em: http://www.cdc.gov/healthywater/ swimming/swimmers/rwi.html

10. Lopes FWA, Júnior APM, Von Sperling E. Metodologia para avaliação de condições de balneabilidade em águas doces no Brasil. Revista Brasileira de Recursos Hídricos 2014; 19(4):124-113.

11. Sanborn M, Takaro T. Recreational water-related illness: Office management and prevention. Can Fam Physician 2013; 59(5):491-495.
12. Lee LH, Lee YD. The impact of water quality on the visual and olfactory satisfaction of tourists. Ocean \& Coastal Management 2015; 105(2015):92-99.

13. Fleisher JM, Kay D. Risk perception bias, self-reporting of illness, and the validity of reported results in an epidemiologic study of recreational water associated illnesses. Marine Pollution Bulletin 2006; 52(3):264-268.

14. Pendleton L, Martin N, Webster DG. Public perceptions of environmental quality: a survey study of beach use and perceptions in Los Angeles County. Marine Pollution Bulletin 2001; 42(11):1155-1160.

15. Middlestad SE, Anderson A, Ramos WD. Beliefs about using an outdoor pool: Understanding perceptions of place in the context of a recreational environment to improve health. Health Place 2015; 34:1-8.

16. Collier C A, Almeida Neto, MS, Aretakis GM, Santos RE, Oliveira T H, Mourão JS, El-Deir AC. Integrated approach to the understanding of the degradation of an urban river: local perceptions, environmental parameters and geoprocessing. Journal of ethnobiology and ethnomedicine 2015; 11(1):1.

17. Julian JP, Doyle MW, Powers SM, Stanley EH, Riggsbee JA. Optical water quality in rivers. Water resources research 2008; 44(10).

18. Wiedenmann A, Krüger P, Dietz K, López-Pila JM, Szewzyk R, Botzenharts K. A randomized controlled trial assessing infectious disease risks from bathing in fresh recreational waters in relation to the concentration of Escherichia coli, intestinal enterococci, Clostridium perfringens, and somatic coliphages. Environ Health Perspect 2006; 114(2):228-236.

19. Kay D, Bartram J, Prüss A, Ashbolt N, Wyer MD, Fleisher JM, Fewtrell L, Rogers A, Rees G. Derivation of numerical values for the World Health Organization guidelines for recreational waters. Water Research 2004; 38(5):1296-1304.

20. Peres F, Rozemberg B, Lucca SR. Percepção de riscos no trabalho rural em uma região agrícola do Estado do Rio de Janeiro, Brasil: agrotóxicos, saúde e ambiente. Cad Saude Publica 2005; 21(6):1836-1844.

21. Gregolis TBL, Pinto WJ, Peres F. Percepção de riscos do uso de agrotóxicos por trabalhadores da agricultura familiar do município de Rio Branco, AC. Revista brasileira de Saúde ocupacional 2012; 37(125):99-113.

22. Chen B, Adimo OA, Bao Z. Assessment of aesthetic quality and multiple functions of urban green space from the users' perspective: the case of Hangzhou Flower Garden, China. Landscape and Urban Planning 2009; 93(1):76-82.

23. Moser G. Water quality perception, a dynamic evaluation. Water Sci Technol 1984; 4(3):201-210. 
24. Völker S, Kistemann T. I’m always entirely happy when I'm here!" Urban blue enhancing human health and well-being in Cologne and Düsseldorf, Germany. Soc Sci Med 2013; 78:113-124.

25. Barbour MT, Gerritsen J, Snyder BD, Stribling JB. Biological Data Analysis. In: Barbour MT, Gerritsen J, Snyder BD, Stribling JB, editors. Rapid Bioassessment Protocols for Use in Streams and Wadeable Rivers: Periphyton, Benthic Macroinvertebrates and Fish. Washington: U.S. Environmental Protection Agency; Office of Water; 1999. p. 9-15.

26. Brasil. Ministério do Meio Ambiente. Resolução Conama $n^{\circ} 274$, de 29 de novembro de 2000. Define os critérios de balneabilidade em águas brasileiras. Diário Oficial da União 2001; 25 jan.

27. Water Environmental Federation, American Public Health Association. Standard methods for the examination of water and wastewater. Washington: American Public Health Association; 2005.

28. Roca E, Villares M. Public perceptions for evaluating beach quality in urban and semi-natural environments. Ocean \& Coastal Management 2008; 51(4):314-329.

29. Hunter PR, Fewtrell L. Acceptable risk. In: Fewtrell L, Bartram J, editors. Water Quality: Guidelines, Standards and Health-Assessment of risk and risk management for water-related infectious disease. London: WHO; 2001. p. 207-229.

30. McCullough IM, Loftin CS, Sader SA. Landsat imagery reveals declining clarity of Maine's lakes during 19952010. Freshwater Science 2013; 32(3):741-752.

31. Buss DF, Carlisle DM, Chon TS, Culp J, Harding JS, Keizer-Vlek HE, Hughes RM. Stream biomonitoring using macroinvertebrates around the globe: a comparison of large-scale programs. Environmental monitoring and assessment, 2015; 187(1):1-21.

32. Le Lay YF, Piégay H, Rivière-Honegger A. Perception of braided river landscapes: Implications for public participation and sustainable management. Journal of Environmental Management 2013; 119:1-12

33. Mocior E, Kruse M. Educational values and services of ecosystems and landscapes - An overview. Ecological Indicators 2016; 60:137-151.

34. Lamparelli CC, Pogreba-Brown K, Verhougstraete M, Sato MIZ, Castro Bruni A, Wade TJ, Eisenberg JN. Are fecal indicator bacteria appropriate measures of recreational water risks in the tropics? A cohort study of beach goers in Brazil. Water research 2015; 87(15):5968.

35. Kramer TA, Liu J. Enumeration of coliform bacteria in wastewater solids using defined substrate technology. Water Environ Res 2002; 4(6):526-530.
36. Pisciotta JM, Rath DF, Stanek PA, Flanery DM, Harwood VJ. Marine bacteria cause false-positive results in the Colilert-18 rapid identification test for Escherichia coli in Florida waters. Appl Environ Microbiol 2002; 68(2):539-544.

37. Luyt CD, Tandlich R, Muller WJ, Wilhelmi BS. Microbial monitoring of surface water in South Africa: an overview. Int J Environ Res Public Health 2012; 9(8):2669-2693.

38. Azevedo, MV. Estudo da relação entre Hepatite A e condições de balneabilidade em cenários de saneamento precário na região de Mangaratiba, Baía de Sepetiba-RJ [dissertação]. Rio de Janeiro: Fundação Osvaldo Cruz; 2000.

39. França PTR, Melloni R. Avaliação microbiológica de águas de recreação por meio da análise de resistência de bactérias heterotróficas a antibióticos. RBRH - Revista Brasileira de Recursos Hídricos 2014; 19(4):107-113.

40. Artell J, Heini A, Eija P. Subjective vs. objective measures in the valuation of water quality. Journal of Environmental Management 2013; 130:288-296.

41. Real E, Arce C, Sabucedi JM. Classification of landscapes using quantitative and categorical data, and prediction of their scenic beauty in North-Western Spain. Journal of Environmental Psychology 2000; 20:355-373.

42. Cottet M, Piégay H, Bornette G. Does human perception of wetland aesthetics and healthiness relate to ecological functioning? Journal of Environmental Management 2013; 128:1012-1022.

Artigo apresentado em 24/08/2016

Aprovado em 20/10/2016

Versão final apresentada em 22/10/2016 
